\title{
RESISTÊNCIA MECÂNICA DO SOLO E FORÇA DE TRAÇÃO EM HASTES SULCADORAS DE SEMEADORAS-ADUBADORAS EM SISTEMA DE INTEGRAÇÃO LAVOURA-PECUÁRIA
}

\section{OSMAR CONTE ${ }^{1}$, RENATO LEVIEN ${ }^{2}$, CARLOR R. TREIN ${ }^{2}$, MICHAEL MAZURANA ${ }^{3}$, HENRIQUE DEBIASI ${ }^{4}$}

RESUMO: A integração lavoura-pecuária, realizada mediante a implantação de pastagens no inverno e a semeadura de milho ou soja no verão, constitui-se numa alternativa para a diversificação de atividades e ampliação dos lucros. Animais em pastejo, principalmente em áreas agrícolas manejadas sob semeadura direta, podem resultar na compactação adicional do solo, diagnosticada geralmente pelo aumento de resistência do solo à penetração (RP). Com o objetivo de avaliar a correlação entre RP e força de tração (FT) medida em hastes sulcadoras de semeadoras-adubadoras, nos anos de 2004 e 2005, foi conduzido um experimento em São Miguel das Missões - RS, em Latossolo Vermelho ( $0.540 \mathrm{~kg} \mathrm{~kg}^{-1}$ de argila). Os tratamentos consistiram em quatro intensidades de pastejo, que resultaram em alturas de pastagem de 10;20;30 e $40 \mathrm{~cm}$, e de testemunha sem pastejo, organizados em DBC, com três repetições. Avaliou-se a RP, no final do período de pastejo, e na semeadura da soja, obteve-se a FT exigida nas hastes sulcadoras de semeadoras-adubadoras. A RP e a FT aumentaram com o incremento na intensidade de pastejo. A correlação entre essas variáveis foi significativa, comprovando que é possível avaliar o estado de compactação do solo por meio da medição da FT requerida pelas hastes sulcadoras de semeadoras-adubadoras.

PALAVRAS-CHAVE: compactação do solo, semeadura direta, pastejo.

\section{MECHANICAL RESISTANCE OF SOIL AND TRACTION FORCE BY PLANTER CHISEL TYPE OPENERS IN CROP-LIVESTOCK SYSTEM}

\begin{abstract}
The use of crop-livestock integration systems, with forage implantation during winter and corn or soybean sown during summer, has become an alternative to activity diversification while magnifying profits. Cattle grazing, mainly in agricultural areas under notillage, can result in additional soil compaction, which can usually be diagnosed by increases in soil resistance to penetration (RP). Aiming to evaluate the correlation between RP and traction force (FT) measured with cutting shafts, in the years of 2004 and 2005, an experiment was conducted in São Miguel das Missões - RS, Brazil, in an Oxisoil (0.540 kg kg${ }^{-1}$ clay content). Treatments consisted of four grazing intensities, which resulted in pasture heights of $10 ; 20 ; 30$ and $40 \mathrm{~cm}$, and a no-grazed area used as blank, designed in randomized blocks with three replicates. After the grazing period and during soybean sowing, RP was evaluated; also, required power to openers chisel type coulter was measured. Both parameters increased with increments in grazing intensity. There was correlation between both parameters, showing that it is possible to evaluate the condition of soil's compaction by measuring draft requirement by fertilizer furrow openers.
\end{abstract}

KEYWORDS: soil compaction, no tillage, grazing.

\footnotetext{
${ }^{1}$ Doutorando do Programa de Pós-Graduação em Ciência do Solo, Departamento de Solos, Faculdade de Agronomia, UFRGS, Av. Bento Gonçalves, 7712, Porto Alegre - RS, agroconte@yahoo.com.br. Bolsista CNPq.

${ }^{2}$ Prof. Adjunto, Departamento de Solos, Faculdade de Agronomia, UFRGS, Av. Bento Gonçalves, 7712, Porto Alegre - RS.

${ }^{3}$ Aluno de graduação, Faculdade de Agronomia, UFRGS, bolsista de iniciação científica.

${ }^{4}$ Pesquisador A, Embrapa Soja, Londrina - PR.

Recebido pelo Conselho Editorial em: 26-3-2008
}

Aprovado pelo Conselho Editorial em: 7-10-2008 


\section{INTRODUÇÃO}

O Planalto Médio Gaúcho é uma região tradicional de produção de grãos de milho e de soja durante o verão no RS. As condições edafoclimáticas dessa região tornam-na adequada ao cultivo, no inverno, de cereais como o trigo e a cevada. Entretanto, o baixo retorno econômico propiciado pelos cereais de estação fria tem motivado os produtores a buscarem novas alternativas para o inverno, entre as quais se destaca a implantação de pastagens temporárias, em sua maioria constituída por gramíneas forrageiras (aveia-preta, azevém, ou consórcio de ambas), destinadas, principalmente, à terminação de bovinos de corte. Tal situação configura um sistema de integração lavoura-pecuária (ILP). No entanto, se não houver adequação da intensidade de pastejo, o pisoteio animal pode resultar na compactação do solo (KOCHHANN et al., 2000; BOTTA et al., 2006), principalmente se o mesmo ocorrer sob elevados teores de água no solo (JORAJURÍA COLAZO, 2005). A importância desse problema cresce porque a maior parte das áreas agrícolas nessa região são manejadas sob semeadura direta. $\mathrm{O}$ processo de compactação do solo, ao aumentar a sua densidade e a sua resistência mecânica à penetração (RP), bem como ao reduzir o volume de macroporos, a capacidade de infiltração de água, a aeração e a condutividade hidráulica (DIAS JÚNIOR \& PIERCE, 1996), pode resultar na diminuição da produtividade das culturas (BEUTLER et al., 2005) e em prejuízos ao ambiente. Além da compactação do solo, o pastejo intenso poderá diminuir o carbono orgânico do solo pela redução da entrada de biomassa e pela aceleração da taxa de respiração (CAO et al., 2004).

O uso de hastes sulcadoras para a deposição do adubo, durante a semeadura das culturas estivais, ao ocasionar maior mobilização de solo comparativamente aos discos duplos (MNZTFA (1998), constitui-se em uma alternativa para contornar problemas relacionados à compactação superficial do solo que, além de ser a mais prejudicial ao crescimento das plantas (UNGER \& KASPAR, 1994), é a de ocorrência mais comum em áreas submetidas a pisoteio animal (BROCH et al., 1997). Além disso, o uso de hastes sulcadoras permite a deposição do fertilizante a maiores profundidades, o que pode estimular o aprofundamento das raízes, tendo em vista que os nutrientes, em semeadura direta, tendem a se concentrar na superfície do solo e, desse modo, minimizar os efeitos da compactação sobre o crescimento das plantas. Porém, o emprego de hastes sulcadoras, em substituição aos discos duplos, aumenta o requerimento de força de tração (FT) e o consumo de combustível, diminuindo a velocidade de deslocamento do conjunto trator/semeadora, comparado o mesmo número de linhas (SILVA, 2003).

A FT demandada por hastes sulcadoras que equipam semeadoras-adubadoras pode ser afetada, entre outros fatores, pelo estado de compactação do solo (SÁNCHEZ-GIRÓN et al., 2005). Diante disso, é possível que o aumento da intensidade de pastejo resulte em incremento da demanda de tração das hastes sulcadoras, evidenciando, assim, a existência de correlação significativa entre essa variável e o grau de compactação do solo. Tal fato possibilitaria o uso da FT como indicador do estado de compactação do solo, conforme sugerido por CEPIK et al. (2005) e MOUAZEN \& RAMON (2006). Entretanto, a relação FT x grau de compactação pode ser modificada quando do uso de hastes com geometrias diferentes ou mediante alteração da profundidade de atuação, pois esses são alguns dos fatores que influenciam na FT exigida pelas hastes sulcadoras (CONTE et al., 2007). Cabe ainda salientar que o estudo de correlação entre a FT demandada por hastes sulcadoras e o estado de compactação exige a utilização de indicador confiável da magnitude desse último. A RP é um dos indicadores do estado de compactação do solo mais utilizado atualmente, devido à facilidade e à rapidez de execução do ensaio (CHANCELLOR, 1994), bem como sua maior sensibilidade a mudanças do manejo comparativamente à densidade do solo (BOTTA et al., 2006).

Assim, o objetivo deste trabalho foi estudar o efeito da intensidade de pastejo sobre a RP e a FT demandada por alguns modelos de hastes sulcadoras de adubo atuando a diferentes profundidades, bem como verificar se essas variáveis apresentam correlação significativa. 


\section{MATERIAL E MÉTODOS}

O experimento onde o estudo foi conduzido, encontra-se instalado na Fazenda do Espinilho, localizada no município de São Miguel das Missões - RS, região fisiográfica do Planalto Médio, a $2^{\circ} 03^{\prime}$ de latitude sul, $53^{\circ} 50^{\prime}$ de longitude oeste e à altitude média de $465 \mathrm{~m}$. O solo é classificado como Latossolo Vermelho distroférrico, com $0,540 \mathrm{~kg} \mathrm{~kg}^{-1}$ de argila. A área experimental vem sendo conduzida desde 1994 sob semeadura direta, com soja no verão e aveia-preta e azevém no inverno.

O experimento engloba área de aproximadamente 22 ha, divididos em 14 parcelas de diferentes tamanhos, arranjadas no delineamento experimental de blocos casualizados, com três repetições. Os tratamentos constaram de quatro intensidades de pastejo representadas por quatro alturas da pastagem $(10 ; 20 ; 30$ e $40 \mathrm{~cm})$, e uma testemunha sem pastejo (SP). Foram utilizados três animais-teste por parcela, juntamente com um número variável de animais reguladores, que foram adicionados ou retirados das referidas parcelas visando à manutenção das alturas de pastejo propostas, configurando cargas animais entre 1,5 e 4,5 unidades animal (UA) por hectare. O pastejo ocorreu simultaneamente em todas as parcelas, iniciando em meados de julho, estendendo-se até a segunda quinzena de novembro, completando cerca de 120 dias em ambos os anos de avaliação. Dessa forma, a permanência dos animais na área deu-se nos mais variados perfis de umidade do solo, considerando que a referida região apresenta distribuição normal de chuvas, com média para o período ultrapassando os $100 \mathrm{~mm}$ mensais.

A força de tração (FT) requerida pelas hastes sulcadoras para a deposição do adubo foi medida durante a semeadura direta da soja, nas safras 2004/2005 e 2005/2006. Foram utilizados quatro modelos de hastes sulcadoras de adubo que equipam as marcas comerciais Stara Sfil e Vence Tudo, designadas como (HN, HI, HL e SF), e com as quais se obtiveram as quatro profundidades teóricas de atuação $(6 ; 9 ; 12$ e $15 \mathrm{~cm})$, que resultaram em profundidades efetivas de trabalho de 6; 8,$3 ; 13,2$ e $15,3 \mathrm{~cm}$.

$\mathrm{O}$ modelo $\mathrm{HN}$ refere-se às hastes que normalmente equipam as semeadoras-adubadoras Vence Tudo, enquanto o modelo $\mathrm{HL}$ diz respeito à haste mais longa, que poderia atingir $18 \mathrm{~cm}$ na profundidade de atuação. O modelo HI mantém as características estruturais das demais e apresenta comprimento intermediário. O modelo aqui designado como SF faz menção às hastes sulcadoras utilizadas pelo fabricante Stara Sfil.

$\mathrm{Na}$ safra 2004/2005, avaliaram-se as hastes HN, HI e HL, que foram montadas em uma semeadora-adubadora de cinco linhas, marca Vence Tudo, modelo 11500, com espaçamento entre linhas de $40 \mathrm{~cm}$, tracionada por trator da marca John Deere 5600, com tração dianteira auxiliar (TDA) e potência máxima no motor de $53 \mathrm{~kW}(76 \mathrm{cv})$, à velocidade média de $5,6 \mathrm{~km} \mathrm{~h}^{-1}$. Os modelos HN, HI e HL apresentam espessura da haste e da ponteira de $0,0127 \mathrm{~m} \mathrm{e} 0,0257 \mathrm{~m}$, respectivamente, ângulo de ataque $18^{\circ}$ e comprimento de 0,$415 ; 0,440$ e $0,475 \mathrm{~m}$, respectivamente.

Já em 2005/2006, a haste empregada foi a SF, que equipou uma semeadora-adubadora de oito linhas, marca Stara Sfil, modelo SS 8000, com espaçamento entre linhas de $45 \mathrm{~cm}$ (SF), tracionado por um trator da marca CBT, modelo 2100, 4x2, com potência máxima no motor de $77 \mathrm{~kW}$ $(105 \mathrm{cv})$, à velocidade de $4,5 \mathrm{~km} \mathrm{~h}^{-1}$. O modelo SF é caracterizado por espessura da haste e da ponteira de $0,010 \mathrm{~m}$ e $0,02275 \mathrm{~m}$, respectivamente, ângulo de ataque $20^{\circ}$ e comprimento de $0,390 \mathrm{~m}$.

Para a medição dos valores de FT nas hastes, foram instalados, no suporte das linhas, extensômetros de resistência elétrica ("strain gages"), capazes de medir a deformação ocorrida no suporte quando em operação. A aquisição de dados foi executada com frequência de cinco leituras por segundo, sendo os mesmos armazenados por "datalogger" da marca CAMPBEL SCIENTIFIC, modelo CR23X.

A RP foi determinada por meio de penetrômetro com características estruturais em acordo com a norma ASAE S313.3 (ASAE, 2004), dotado de sistema eletrônico de medição e aquisição 
dos dados de força aplicada e a respectiva posição (profundidade) no solo. Foram executadas 15 leituras de resistência mecânica do solo à penetração (RP) por parcela, até $18 \mathrm{~cm}$ de profundidade, divididas em três transectas. Assim, cada transecta foi composta por cinco leituras obtidas lado a lado, espaçadas de $40 \mathrm{~cm}$. Paralelamente, procedeu-se à avaliação da umidade gravimétrica do solo (Ug).

O tratamento estatístico dos dados envolveu a execução de análise de regressão linear, utilizando-se como variável independente da altura da pastagem e como variável dependente a RP e a FT. Realizou-se, também, análise de correlação entre os dados de RP e FT. No intuito de possibilitar a execução das análises anteriormente mencionadas, foi necessário atribuir um valor de altura para a testemunha sem pastejo. $\mathrm{O}$ valor considerado correspondeu à maior altura atingida pelas plantas desse tratamento durante o ciclo de desenvolvimento da pastagem $(50,7$ e $55,2 \mathrm{~cm}$ nos anos de 2004 e 2005, respectivamente), o que ocorreu no início de setembro. Para as análises realizadas, utilizou-se do valor médio das alturas medidas em 2004 e 2005. As análises de regressão, quanto as de correlação, foram executadas com o software estatístico "ESTAT", desenvolvido pela Universidade Estadual Paulista (UNESP).

\section{RESULTADOS E DISCUSSÃO}

Em ambos os anos de avaliação, a Ug no momento da semeadura da soja diminuiu com o aumento da intensidade de pastejo. Em 2004, a Ug variou de 0,24 a 0,30 kg kg-1, aumentando do tratamento com $10 \mathrm{~cm}$ de altura de pastagem para o tratamento SP. No segundo ano (2005), o solo encontrava-se mais seco, de modo que os valores de Ug oscilaram entre 0,12 e $0,20 \mathrm{~kg} \mathrm{~kg}^{-1}$. Novamente, obteve-se menor conteúdo de água no solo onde a pastagem foi mais intensamente pastejada. De acordo com CHEN et al. (2004) e TABOADA (2005), esse efeito é explicado pela maior cobertura de solo proporcionada pelos resíduos de forragem, o que colabora para diminuir a perda de água para a atmosfera. MELLO et al. (2004), estudando efeitos de pastejo com espécie tropical, afirmam que a quantidade de resíduo remanescente ao pastejo é suficiente para a manutenção do sistema plantio direto.

Observa-se, na Figura 1, que a RP medida nas profundidades de 6 e $12 \mathrm{~cm}$ diminuiu de forma linear e significativa com o aumento da altura da pastagem. Isso demonstra que a RP, nessas profundidades, aumentou em função do incremento no número de animais em pastejo na mesma área, o que pode ser atribuído à compactação do solo ocasionada pelo pisoteio animal e, também, ao menor teor de água observado nos tratamentos envolvendo maiores intensidades de pastejo. Tal justificativa baseia-se no fato de os valores de RP aumentarem, em função do incremento da densidade e da redução do teor de água do solo (KLEIN et al., 1998). Esses resultados estão em consonância com os obtidos por ANDREOLA \& GABRIEL FILHO (2006), que concluíram que o pastejo em área de integração lavoura-pecuária alterou as características físicas do solo, com efeito mais acentuado em condições de pastejo com solo úmido.

Conforme REINERT et al. (2007), penetrômetros auxiliam na determinação e na avaliação da resistência mecânica de solos agrícolas, relacionando-a com compactação do solo e crescimento do sistema radicular das plantas. Ainda, conforme a Figura 1, verifica-se que o ajuste dos dados de RP medidos a $18 \mathrm{~cm}$ de profundidade em relação às alturas de pastagem não foi estatisticamente significativo, embora a tendência de variação da RP com as intensidades de pastejo tenha sido semelhante às demais profundidades. Isso evidencia que as pressões aplicadas em virtude do pisoteio animal não foram suficientes para aumentar de forma pronunciada o grau de compactação do solo a $18 \mathrm{~cm}$ de profundidade. Tal fato corrobora BROCH et al. (1997), que afirmam que a compactação do solo ocasionada pelo pisoteio animal, além de temporária, restringe-se à superfície do solo. A diminuição dos efeitos do pisoteio animal sobre o grau de compactação, com o aumento da profundidade, torna-se mais evidente quando se analisam os coeficientes angulares das equações apresentadas na Figura 1. Verifica-se que o coeficiente angular (inclinação da reta) diminui à medida que a profundidade aumenta, indicando que a RP é menos sensível ao aumento da intensidade do pastejo quando se consideram camadas de solo mais profundas. Segundo 
TERMINELLO et al. (2004), o comportamento mecânico do solo sob tráfego é diferente entre a semeadura direta e o preparo convencional do solo.

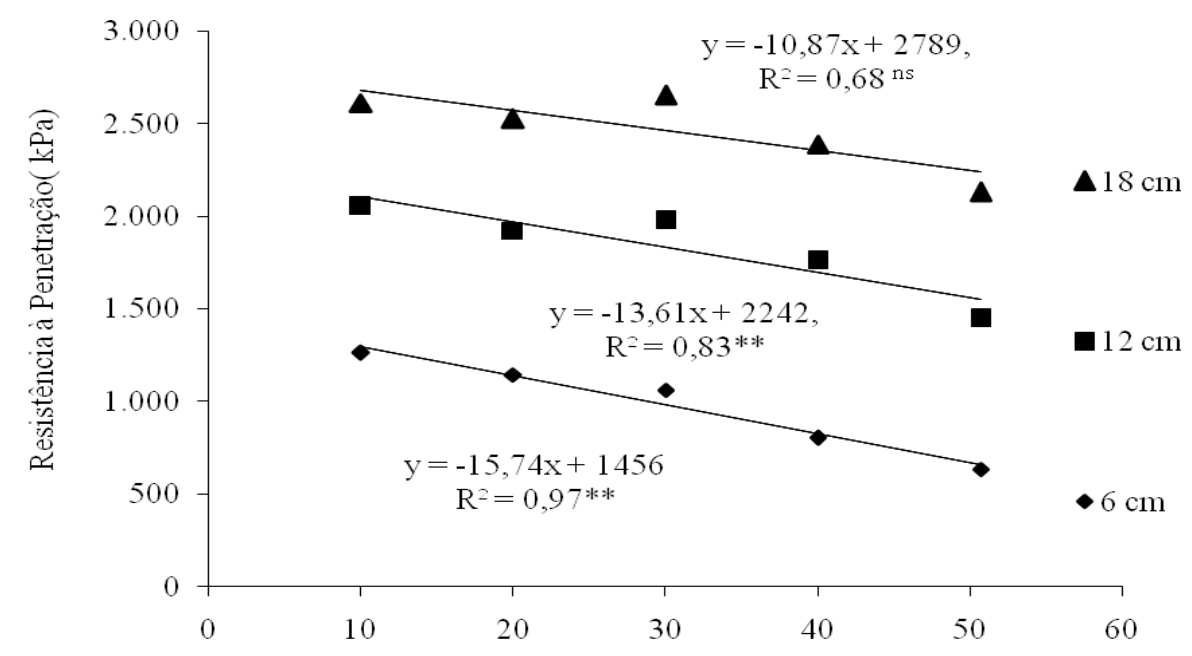

Alturas de Pasto (cm)

** $\mathrm{e}^{*}$ - regressão significativa a $1 \%$ e $5 \%$, respectivamente; ns - não houve significância.

FIGURA 1. Relação entre alturas de pasto e resistência do solo à penetração medida em diferentes profundidades, na semeadura da soja safra 2004/2005. Relationship between pasture heights and soil penetration resistance in different depths, in the sowing of the soybean 2004/2005.

Ao se analisar a relação entre a FT medida na haste sulcadora para a deposição do adubo e a altura da pastagem (Figura 2), nota-se o mesmo comportamento já citado para a RP, ou seja, redução linear e significativa na FT demandada pelas hastes com o aumento na altura da pastagem, independentemente da profundidade de atuação das mesmas. Tal fato pode ser atribuído, em primeiro lugar, ao maior grau de compactação do solo no momento da semeadura, observado nas menores alturas da pastagem. Maiores valores de requerimento de FT por parte de hastes sulcadoras para a deposição do adubo que equipam semeadoras-adubadoras têm sido atribuídos ao aumento no grau de compactação do solo (SÁNCHEZ-GIRÓN et al., 2005; CONTE et al., 2007).

Outro fator que pode estar influenciando na FT requerida pelas hastes nas diferentes intensidades de pastejo empregadas, é o efeito desse sobre o teor de água do solo. Nesse sentido, CEPIK et al. (2005), trabalhando em um solo franco-argilo-arenoso, observaram menores valores de demanda de FT por hastes sulcadoras de semeadoras-adubadoras quando as mesmas atuaram em condições de solo seco, comparativamente à condição friável e seca. Em solo muito argiloso do basalto paranaense, CASÃO JÚNIOR et al. (2000) concluíram que a FT requerida por uma semeadora-adubadora equipada com hastes sulcadoras para deposição do adubo aumentou quando a consistência do solo passou de friável a plástica. Em ambos os trabalhos, os autores atribuíram o aumento da FT com o incremento na umidade e à maior aderência de solo às hastes. Diante disso, é provável que, na avaliação realizada em 2004, o aumento do teor de água do solo, observado da maior para a menor intensidade de pastejo, tenha colaborado para reduzir a magnitude do aumento na FT propiciado pelo maior grau de compactação inerente às menores alturas da pastagem, devido à adesão de solo na haste. Em 2005, quando os teores de água do solo foram mais baixos, é possível que a maior coesão, típica de solos mais secos, tenha-se somado ao efeito do grau de compactação mais elevado detectado nas menores alturas da pastagem, resultando em maior FT nesses tratamentos. 


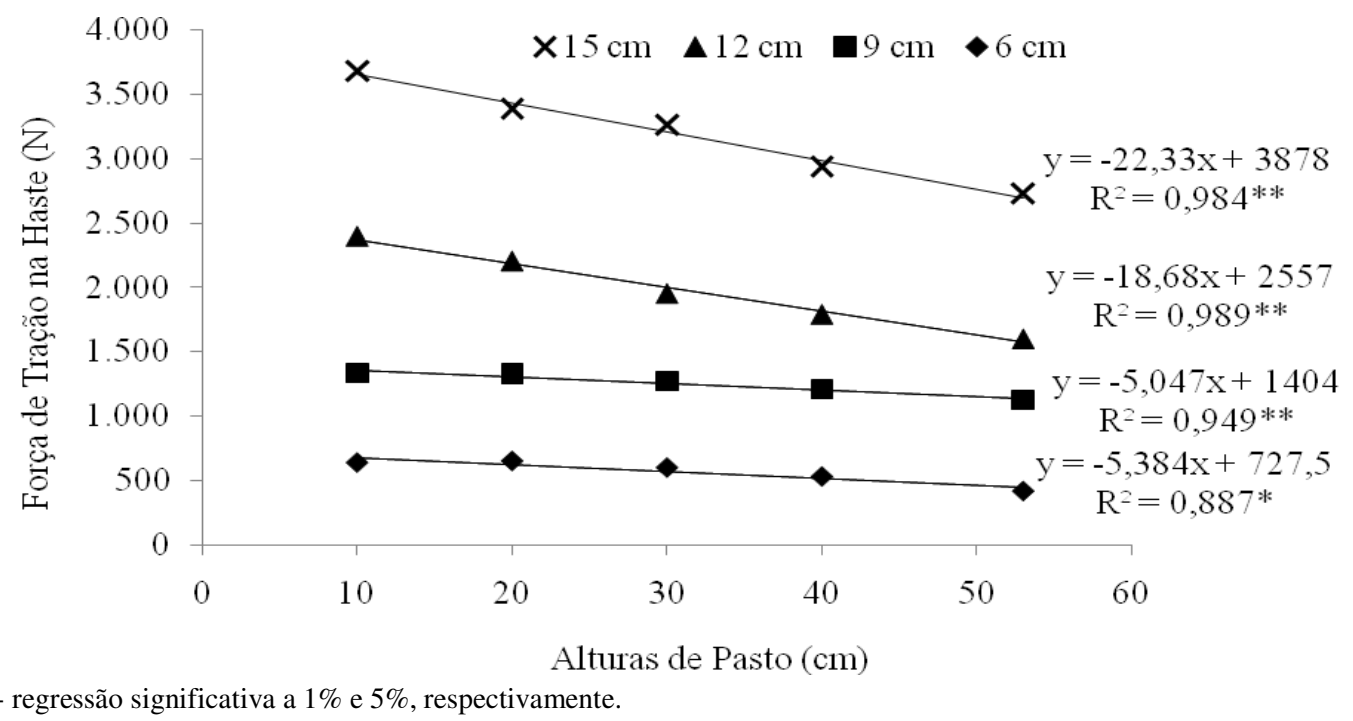

FIGURA 2. Relação entre alturas de pasto e força de tração medida em hastes sulcadoras atuando em diferentes profundidades. Relationship between pasture heights and power requirement by planter chisel openers acting in different depths.

A resposta da FT à intensidade de pastejo variou em função dos tipos de hastes sulcadoras para deposição do adubo (Figura 3). Analisando-se o coeficiente de regressão das equações mostradas na Figura 3, verifica-se que a diminuição da FT com o aumento da altura da pastagem foi mais pronunciada quando do emprego da haste SF (safra 2005/2006), comparativamente aos demais modelos, avaliados na safra 2004/2005. Para os modelos de hastes HI e HL, a relação FT x altura da pastagem não foi estatisticamente significativa. Isso pode estar ligado à geometria das hastes e suas ponteiras, e a influência que esses fatores causam sobre as forças quando em atuação no solo (CHAUDHURI, 2001). Além disso, conforme já discutido anteriormente, o teor de água do solo, quando da avaliação dos modelos HN, HL e HI, foi menor comparativamente à ocasião em que se testou a haste SF. Assim, a maior aderência de solo nesses modelos de hastes devido ao teor de água mais elevado nas menores intensidades de pastejo, possivelmente, tenha reduzido a magnitude do aumento da FT devido ao maior grau de compactação observado nesses tratamentos. Tal fato, provavelmente, não seja válido para a haste SF, devido aos baixos teores de água medidos em todos os tratamentos na safra 2005/2006, de forma que aderência significativa de solo não deve ter ocorrido. É importante considerar ainda que, em geral, o aumento na resistência mecânica do solo em função do estado de compactação do mesmo é mais pronunciado quando o teor de água do solo é baixo (KLEIN et al., 1998), o que foi observado para a haste SF.

Pela Figura 3, é possível visualizar, ainda, que os modelos de hastes estudadas diferiram em termos de FT demandada. O modelo SF apresentou a maior exigência de FT, seguida pelos modelos HI e HL, que demandaram esforço de tração intermediário, aquém da haste SF, porém superior ao modelo HN. A maior FT requerida pelo modelo de haste sulcadora SF pode ser atribuído à maior profundidade de atuação da mesma, bem como ao menor teor de água observado durante a sua avaliação. A FT medida na haste SF poderia ter assumido magnitudes ainda maiores se a velocidade de trabalho fosse igual à empregada nos demais modelos de haste, visto que o aumento na velocidade de deslocamento eleva o esforço demandado (BORTOLOTO et al., 2006). A correlação entre as variáveis RP e FT foi positiva e significativa, tanto para a haste HN (Figura 4), quanto para a SF (Figura 5). Verifica-se, ainda, que esse comportamento ocorreu para as duas profundidades de atuação de cada haste testada, independentemente da geometria da haste e da ponteira e/ou profundidade de atuação. 


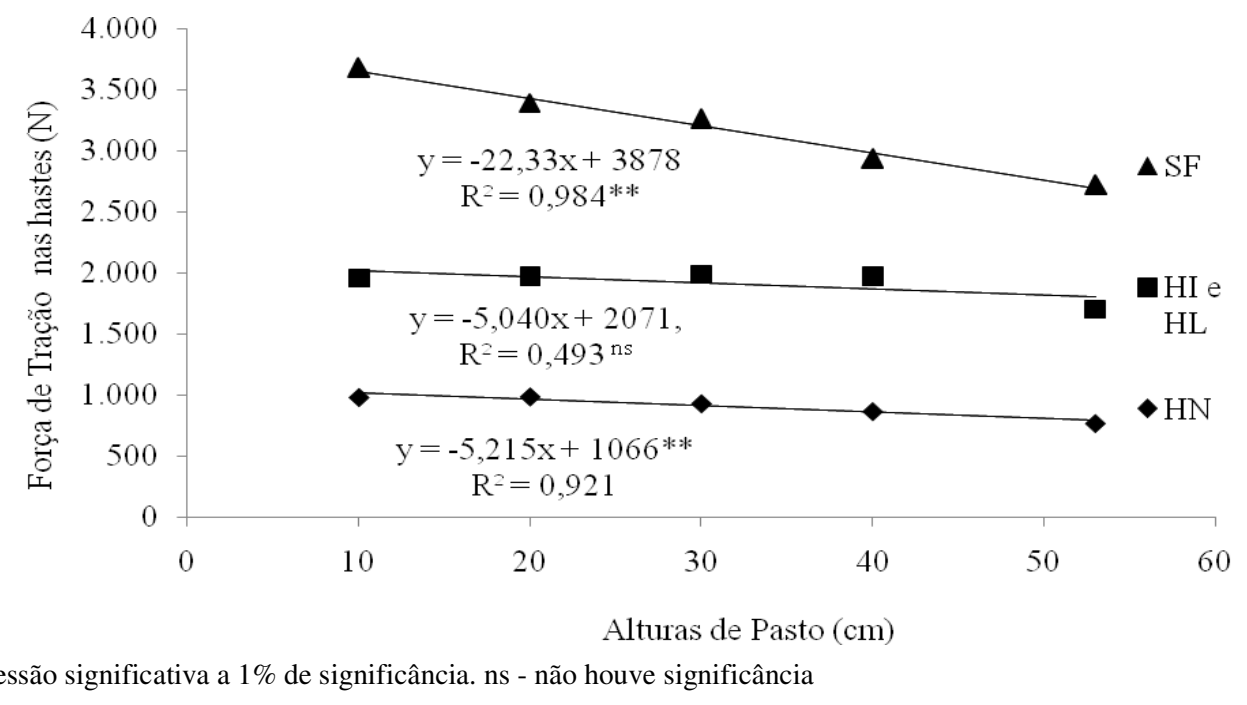

** - regressão significativa a 1\% de significância. ns - não houve significância

FIGURA 3. Relação entre alturas de pasto e força de tração medida em modelos de hastes sulcadoras atuando em diferentes profundidades. Relationship between pasture heights and power requirement in models of planter chisel openers acting in different depths.

No entanto, a análise das Figuras 4 e 5 permite inferir que a resposta da FT à RP e, portanto, ao grau de compactação do solo, variou com a profundidade de trabalho da haste, pois a reta que representa a relação FT x RP foi deslocada para a direita, o que foi mais evidente para a haste SF comparativamente à HN (Figuras 4 e 5). Isso significa que, para a mesma RP, a FT é maior quando a atuação da haste é mais profunda. O aumento da FT com o incremento da profundidade de atuação da haste foi constatado em diversos trabalhos (HERZOG et al., 2004, CEPIK et al., 2005; BEUTLER et al., 2005; CONTE et al., 2007). No caso da haste SF, observa-se, também, que a inclinação da reta foi menor quando a mesma atuou na maior profundidade (Figura 5), demonstrando que, nessa situação, a FT é menos sensível à variação do estado de compactação do solo, representado pela RP. A relação FT x RP também se mostrou diferente para as hastes $\mathrm{HN}$ e SF. É importante lembrar que o teor de água do solo foi menor na semeadura da soja em 2005 , quando a haste sulcadora testada foi a SF. Os efeitos desse fator sobre a resposta da FT ao grau de compactação foram discutidos quando da análise da Figura 3. Esse fato, aliado às diferenças na geometria da haste e da ponteira, possivelmente, explica a maior taxa de aumento da FT com a RP observada para a haste SF em relação à HN (Figuras 4 e 5), quando se compara a mesma profundidade de atuação $(12 \mathrm{~cm})$.

Considerando que a RP é um método clássico e eficiente para o diagnóstico do estado de compactação do solo (CHANCELLOR, 1994) e que, conforme demonstrado neste trabalho (Figuras 4 e 5), essa medida apresenta correlação significativa com a FT medida nas hastes sulcadoras de semeadoras, conclui-se que a mesma é capaz de diagnosticar alterações na estrutura do solo, como a compactação. Dessa forma, o uso de hastes sulcadoras instrumentadas para aquisição dos dados de FT durante a semeadura das culturas de verão, em conjunto com um sistema de posicionamento global (GPS), pode fornecer diagnóstico espacializado do estado de compactação do solo. Esse método pode substituir, ao menos em parte, outras avaliações específicas para esse fim. No entanto, é preciso levar em consideração que a geometria da haste e da ponteira e sua profundidade de atuação, assim como o teor de água do solo, afetam a resposta da FT ao grau de compactação do solo. De modo geral, esses resultados corroboram os obtidos por ADAMCHUK \& MOLIN (2006), que demonstraram que o uso de hastes instrumentadas com sensores de FT e a aquisição georreferenciada de dados permitiram mapeamento de áreas com maior eficiência do que o uso de penetrômetros de cone. 


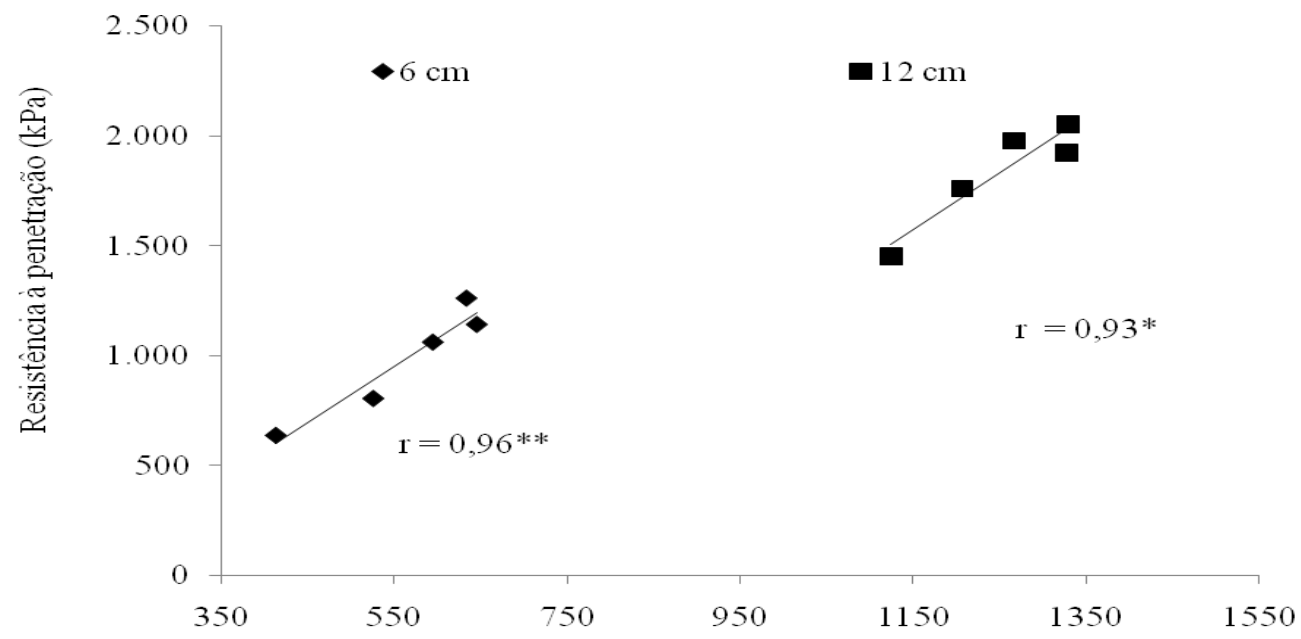

Força de tração $(\mathrm{N})$

** $\mathrm{e}^{*}$ - regressão significativa a $1 \%$ e $5 \%$, respectivamente.

FIGURA 4. Correlação entre resistência do solo à penetração e esforço de tração mensurado na haste sulcadora $\mathrm{HN}$, em duas profundidades. Correlation between soil penetration resistance and power requirement measured in the planter chisel openers $\mathrm{HN}$, in two depths.

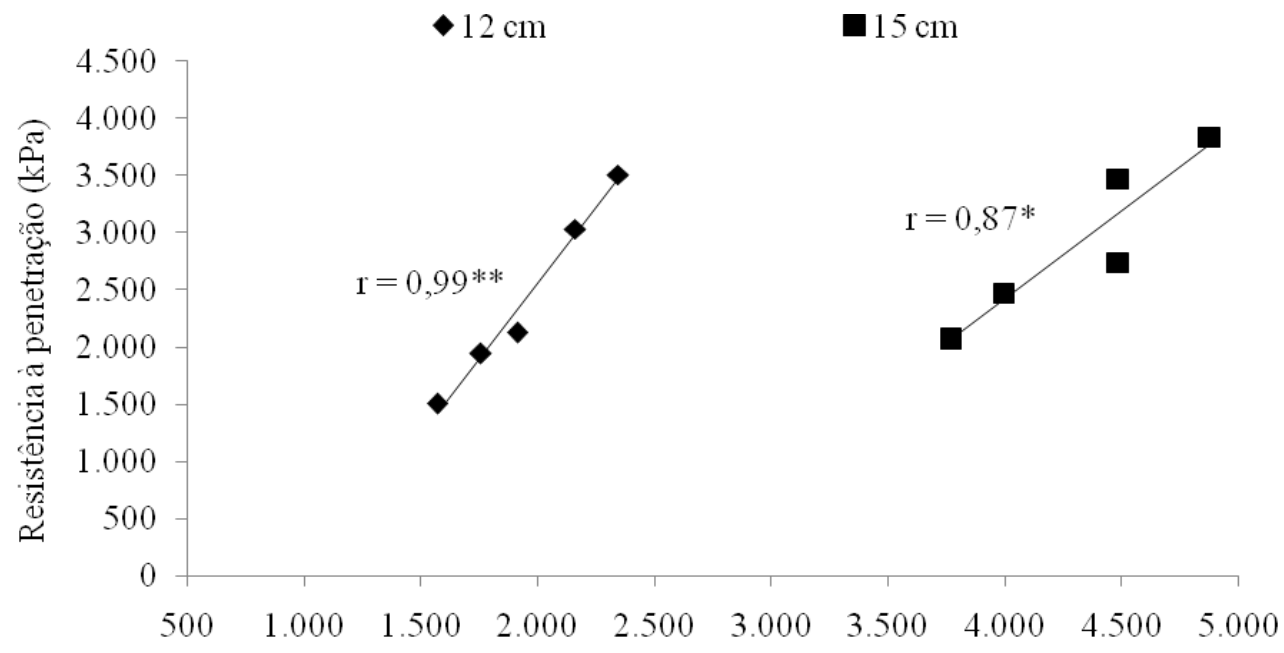

Força de Tração (N)

** $\mathrm{e}^{*}$ - regressão significativa a $1 \%$ e $5 \%$, respectivamente.

FIGURA 5. Correlação entre resistência do solo à penetração e esforço de tração mensurado na haste sulcadora SF, em duas profundidades. Correlation between soil penetration resistance and power requirement measured in planter chisel openers SF, in two depths.

\section{CONCLUSÕES}

Por meio da FT medida nas hastes sulcadoras HN e SF, foi possível diagnosticar o aumento do grau de compactação do solo ocasionado pelo incremento na intensidade de pastejo, que foi significativo até $15 \mathrm{~cm}$ de profundidade. No entanto, o mesmo não foi possível para os modelos de hastes HI e HL. 
A RP e a FT requeridas pelas hastes sulcadoras de semeadoras-adubadoras apresentaram correlação significativa e positiva, evidenciando que essa última variável pode ser útil para o diagnóstico do estado de compactação do solo.

A relação FT x RP variou com o tipo e profundidade de atuação da haste, assim como em função do teor de água do solo. Esses fatores, portanto, devem ser considerados quando do emprego da FT na avaliação do grau de compactação do solo.

\section{REFERÊNCIAS}

ADAMCHUK, V.I.; MOLIN, J.P. Hastes instrumentadas para a mensuração da resistência Mecânica do solo. Engenharia Agrícola, Jaboticabal, v.26, n.1, p.161-9, 2006.

ANDREOLLA, V.R.M.; GABREIL FILHO, A. Demanda de potência de uma semeadora com dois tipos de sulcadores em áreas compactadas pelo pisoteio de animais no sistema integração lavourapecuária. Engenharia Agrícola, Jaboticabal, v.26, n.3, p.768-76, 2006.

ASAE. AMERICAN SOCIETY OF AGRICULTURAL ENGINEERS. Soil Cone Penetrometer ASAE S313.3. St Joseph, 2004. 2 p.

BEUTLER, A.N.; CENTURION, J.F.; ROQUE, C.G.; FERRAZ, M.V. Densidade relativa ótima de Latossolos Vermelhos para a produtividade de soja. Revista Brasileira de Ciência do Solo, Viçosa, v.29, n.6, p.843-9, 2005.

BORTOLOTTO, V.C.; PINHEIRO NETO, R.; BORTOLOTTO, M.C. Demanda energética e uma semeadora-adubadora para soja sob diferentes velocidades de deslocamento e coberturas do solo. Engenharia Agrícola, Jaboticabal, v.26, n.1, p.122-30, 2006.

BOTTA, G.F.; JORAJURIA, D.; ROSATTO, H.; FERRERO, C. Light tractor traffic frequency on soil compaction in the Rolling Pampa region of Argentina. Soil and Tillage Research, Amsterdam, v.86, n.1, p.9-14, 2006.

BROCH, D.L.; PITOL, C.; BORGES, E.P. Integração agricultura-pecuária: plantio direto de soja na integração agropecuária. Maracaju: Fundação MS, 1997. 24 p. Informativo Técnico

CAO, G.; TANG, Y.; MO, W.; WANG, Y.; LI, Y.; ZHAO, X. Grazing intensity alters soil respiration in an alpine meadow on the Tibetan plateau. Soil Biology \& Biochemistry, Oxford, v.36, n.2, p.237-43, 2004.

CASÃO JUNIOR, R.; ARAÚJO, A.G.; RALISCH, R. Desempenho da semeadora-adubadora Magnum 2850 em plantio direto no basalto paranaense. Pesquisa Agropecuária Brasileira, Brasília, v.35, n.3, p.523-32, 2000.

CEPIK, C.T.C.; TREIN, C.R.; LEVIEN, R. Força de tração e volume de solo mobilizado por haste sulcadora em semeadura direta sobre campo nativo, em função do teor de água, profundidade e velocidade de operação. Engenharia Agrícola, Jaboticabal, v.25, n.2, p.447-57, 2005.

CHANCELLOR, W.J. Soil physical properties. In: CHANCELLOR, W. J. (Coord.). Advances in soil dynamics. Saint Joseph: ASAE, 1994. p. 21-254.

CHAUDHURI, D. Performance evaluation of various types of furrow openers on seed drills - a review. Agricultural Engineering Research, Silsoe, v.79, n.2, p.125-37, 2001.

CHEN, Y.; TESSIER, S.; IRVINE, B. Drill and crop performances as affected by different drill configurations for no-till seeding. Soil \& Tillage Research, Amsterdam, v.77, n.1, p.147-55, 2004.

CONTE, O.; LEVIEN, R.; TREIN, C.R.; CEPIK, C.T.C.; DEBIASI, H. Demanda de tração em haste sulcadora na integração lavoura-pecuária com diferentes pressões de pastejo e sua relação com o estado de compactação do solo. Engenharia Agrícola, Jaboticabal, v.27, n.1, p.220-8, 2007. 
DIAS JÚNIOR, M.S.; PIERCE, F. J. O processo de compactação do solo e sua modelagem. Revista Brasileira de Ciência do Solo, Campinas, v.20, n.1, p.175-82, 1996.

HERZOG, R.L. da S.; LEVIEN, R.; TREIN, C.R. Produtividade de soja em semeadura direta influenciada por profundidade do sulcador de adubo e doses de resíduo em sistema irrigado e não irrigado. Engenharia Agrícola, Jaboticabal, v.24, n.3, p.771-80, 2004.

JORAJURÍA COLLAZO, D. Compactación del suelo agrícola inducida por tráfico vehicular. Una Revision. In: JORAJURÍA COLLAZO, D. (Org.) Reologia del suelo agrícola bajo tráfico:

Modificaciones fisico-mecánicas del suelo vinculadas a la compactación debida al tráfico agrario. La Plata: Universidad Nacional de La Plata, 2005. p.39-55.

KLEIN, V.A.; LIBARDI, P.L.; SILVA, A.P. Resistência mecânica do solo à penetração sob diferentes condições de densidade e teor de água. Engenharia Agrícola, Jaboticabal, v.18, n.2, p.45$54,1998$.

KOCHHANN, R.A.; DENARDIN, J.E.; BERTON, A.L. Compactação e descompactação de solos. Passo Fundo: Embrapa Trigo, 2000. 20 p.

MELLO, L.M.M. de; YANO, E.H.; NARIMATSU, K.C.P.; TAKAHASHI, C.M.; BORGHI, E. Integração agricultura-pecuária em plantio direto: produção de forragem e resíduo de palha após pastejo. Engenharia Agrícola, Jaboticabal, v.24, n.1, p.121-9, 2004.

MNZTFA. Zero Tillage. Brandon: Zero Tillage Farmers Association, Leech Printing, 1998. 118 p.

MOUAZEN, A.M.; RAMON, H. Development of on-line measurement system of bulk density based on on-line measured draught, depth and soil moisture content. Soil and Tillage Research, Amsterdam, v.86, n.2, p.218-29, 2006.

REINERT, D.J.; COLLARES, G.L.; REICHERT, J.M. Penetrômetro de cone com taxa constante de penetração no solo: desenvolvimento e teste de funcionalidade. Engenharia Agrícola, Jaboticabal, v.27, n.1, p.304-16, 2007.

SÁNCHEZ-GIRÓN, V.; RAMÍREZ, J.J.; LITAGO, J.J.; HERNANZ, J.L. Effect of soil compaction and water content on the resulting forces acting on three seed drill furrow openers. Soil and Tillage Research, Amsterdam, v.81, n.1, p.25-37, 2005.

SILVA, P.R.A. Mecanismos sulcadores de semeadora-adubadora na cultura do milho (Zea mays L.) no sistema de plantio direto. 2003. 84 f. Dissertação (Mestrado em Energia na Agricultura) Faculdade de Ciências Agronômicas, Universidade Estadual Paulista "Júlio de Mesquita Filho", Botucatu, 2003.

TABOADA, M.A. Efectos del pastoreo y pisoteo animal sobre lãs propriedades física de suelos. In: JORAJURÍA COLLAZO, D. (Org.). Reologia del suelo agrícola bajo tráfico: modificaciones fisico-mecánicas del suelo vinculadas a la compactación debida al tráfico agrario. La Plata: Universidad Nacional de La Plata, 2005. p.131-43.

TERMINIELLO, A.M.; BALBUENA, R.H.; DRAGHI, L.M.; CLAVERIE, J.A.; PALANCAR, T.C.; JORAJURÍA, D. Comportamento mecânico do solo sob tráfego em dois sistemas de preparo do solo. Engenharia Agrícola, Jaboticabal, v.24, n.1, p.158-66, 2004.

UNGER, P.W.; KASPAR, T.C. Soil compaction and root growth: a review. Agronomy Journal, Madison, v.86, n.4, p.759-66, 1994. 